Pacific Journal of Mathematics

A NOTE ON UNCOUNTABLY MANY DISKS 


\section{A NOTE ON UNCOUNTABLY MANY DISKS}

\section{JOSEPH MARTIN}

R. H. Bing has shown [2] that $E^{3}$ (Euclidean three dimensional space) does not contain uncountably many mutually disjoint wild 2spheres. J. R. Stallings has given an example [6] to show that $E^{3}$ does contain uncountably many mutually disjoint wild disks. It is the goal of this note to show that $E^{3}$ does not contain uncountably many mutually disjoint disks each of which fails to lie on a 2-sphere in $E^{3}$. (A disk which fails to lie on a 2-sphere is necessarily wild.) For definitions the reader is referred to [1].

THEOREM 1. If $V$ is an uncountable collection of mutually disjoint disks in $E^{3}$ then there exists a disk $D$ of the collection $V$ such that $D$ lies on a 2-sphere in $E^{3}$.

The proof of Theorem 1 follows immediately from the following three lemmas.

Lemma 1. If $V$ is an uncountable collection of mutually disjoint disks in $E^{3}$ then there exists an uncountable subcollection $V^{*}$ of $V$ such that if $D$ belongs to $V^{*}, x$ is an interior point of $D$, ax is an arc intersecting $D$ only in the point $x$, and $\varepsilon$ is a positive number then there exists an uncountable subcollection $V_{1}$ of $V^{*}$ such that if $D_{1}$ is an element of $V_{1}$ then (i) $D_{1} \cap a x \neq \phi$ and (ii) there is a homeomorphism of $D_{1}$ onto $D$ which moves no point more than $\varepsilon$.

Proof. Let $V$ be an uncountable collection of mutually disjoint disks in $E^{3}$. Let $V^{\prime}$ denote the subcollection of $V$ defined as follows: $D$ is an element of $V^{\prime}$ if and only if there exist a point $x$ of Int $D$, an arc $a x$ intersecting $D$ only in $x$, and a positive number $\varepsilon$ such that there is no uncountable subcollection $V_{1}$ of $V$ such that if $D_{1}$ belongs to $V_{1}$ then (i) $D_{1} \cap a x \neq \phi$ and (ii) there is a homeomorphism of $D_{1}$ onto $D$ which moves no point more than $\varepsilon$.

It is clear that in order to establish Lemma 1 it is sufficient to show that the collection $V^{\prime}$ is countable. Suppose that $V^{\prime}$ is uncountable.

For each element $D_{\alpha}$ of $V^{\prime}$ let an arc $a_{\alpha}$ and a positive number $\varepsilon_{a}$ be chosen such that (i) the common part of $D_{a}$ and $a_{a}$ is an endpoint of $a_{a}$ which is on the interior of $D_{\alpha}$, and (ii) $a_{a}$ intersects only a countable number of elements $D$ of $V$ such that there is a homeomorphism of $D$ onto $D_{\alpha}$ which moves no point by more than $\varepsilon_{\alpha}$.

Received January 15, 1963. This paper was witten while the author was a postdoctoral fellow of The National Science Foundation. 
Let $\varepsilon$ be a positive number and $V^{\prime \prime}$ be an uncountable subcollection of $V^{\prime}$ such that if $D_{a}$ is an element of $V^{\prime \prime}$ then $\varepsilon<\varepsilon_{a}$.

Let $E$ be a disk and $v$ be an arc such that the common part of $E$ and $v$ is an endpoint of $v$ which is on the interior of $E$. For each element $D_{a}$ of $V^{\prime \prime}$ let $h_{\alpha}$ be a homeomorphism of $E \cup v$ onto $D_{a} \cup a_{\alpha}$. Now $\left\{h_{\alpha} ; D_{a} \in V^{\prime \prime}\right\}$ with the distance function

$$
D\left(h_{\alpha}, h_{\beta}\right)=\max _{t \in E \cup v} \rho\left(h_{\alpha}(t), h_{\beta}(t)\right)
$$

is a metric space. In [3] (Theorem 2) Borsuk shows that this metric space is separable. It follows that there exists an element $D_{a_{0}}$ of $V^{\prime \prime}$ such that if $\delta$ is a positive number then $\left\{h_{\beta} ; D\left(h_{\beta}, h_{\alpha}\right)<\delta\right\}$ is uncountable. Let $h_{\alpha_{0}}$ be denoted by $h_{0}, h_{0}(E)$ be denoted by $D_{0}$, and $h_{0}(v)$ be denoted by $a_{0}$.

Let the endpoints of $a_{0}$ be denoted by $x$ and $y$ and assume that the notation is chosen so that $y \in \operatorname{Int} D_{0}$. Let $z y x$ be an arc such that $a_{0} \subset z y x$ and $z y x$ pierces $D_{0}$ at $y$. Let $z w x$ be an arc in $E^{3}-D_{0}$ such that $z w x \cap z y x=\{z, x\}$, and let $J$ denote the simple closed curve $z y x \cup z w x$. Since $J \cup D_{0}=\{y\}$ it follows that $B d D_{0}$ links $J$.

Now let $\varepsilon_{1}$ be a positive number such that $2 \varepsilon_{1}$ is less than the minimum of $\varepsilon$, dist $\left(J, B d D_{0}\right)$, and dist $\left(z w x, D_{0}\right)$.

Let $H$ be $\left\{h_{\beta} ; D\left(h_{\beta}, h_{0}\right)<\varepsilon_{1} / 2\right\}$, and let $V^{\prime \prime \prime}$ be the set of all elements of $V^{\prime \prime}$ such that $D \in V^{\prime \prime \prime}$ if and only if there exists an element $h$ of $H$ such that $h(E)=D$. Now if $D_{1}$ and $D_{2}$ are two elements of $V^{\prime \prime \prime}$ then there exists a homeomorphism of $D_{1}$ onto $D_{2}$ that moves no point more than $\varepsilon_{1}$.

Suppose that $D$ is an element of $V^{\prime \prime \prime}$. Then since $2 \varepsilon_{1}<\operatorname{dist}\left(J, B d D_{0}\right)$, $B d D_{0}$ links $J$, and there is a homeomorphism of $D_{0}$ onto $D$ which moves no point more than $\varepsilon_{1} / 2$ it follows that $B d D$ links $J$, and hence that $J \cap D \neq \phi$. Since $2 \varepsilon_{1}<\operatorname{dist}\left(z w x, D_{0}\right), D \cap z y x \neq \phi$.

Now for each element $D_{a}$ of $V^{\prime \prime \prime}$ let $P_{\alpha}$ be the greatest point of $D_{a} \cap z y x$ in the order from $z$ to $x$ on $z y x$. Now there exists an element $D_{\gamma}$ of $V^{\prime \prime \prime}$ such that for uncountably many elements $D_{a}$ of $V^{\prime \prime \prime}$, $P_{\alpha}$ is greater than $P_{\gamma}$. But since $2 \varepsilon_{1}<\operatorname{dist}\left(x, D_{0}\right), 2 \varepsilon_{1}<\operatorname{dist}\left(J, B d D_{0}\right)$, and for each element $D_{a}$ of $V^{\prime \prime \prime}$ there is a homeomorphism of $D_{0} \cup a_{0}$ onto $D_{a} \cup a_{\alpha}$ which moves no point more than $\varepsilon_{1} / 2$, it follows that $a_{\gamma}$ intersects every element $D_{a}$ of $V^{\prime \prime \prime}$ such that $P_{a}$ is greater than $P_{\gamma}$. This is because $a_{\gamma}$ may be completed to a simple closed curve $J^{\prime}$ which links $B d D_{a}$ and which intersects $D_{a}$ only in $a_{\gamma}$. Hence $a_{\gamma}$ intersects uncountably many elements of the collection $V^{\prime \prime \prime}$. This is contradictory to the way in which $a_{\gamma}$ was chosen and it follows that the collection $V^{\prime}$ is countable. This establishes Lemma 1.

Lemma 2. Suppose that $V$ is an uncountable collection of mutu- 
ally disjoint disks in $E^{3}$. Then there exists a disk $D$ of the collection $V$ such that $D$ is locally tame at each point of Int $D$.

Proof. Let $V$ be an uncountable collection of mutually disjoint disks in $E^{3}$. Let $V^{*}$ be an uncountable subcollection of $V$ satisfying the conclusion of Lemma 1 . Let $D$ be an element of the collection $V^{*}$ and let $p$ be an interior point of $D$. By Theorem 5 of [1] there exists a subdisk $D^{\prime}$ of $D$ and a 2 -sphere $S$ in $E^{3}$ such that $p \in \operatorname{Int} D^{\prime}$ and $D^{\prime} \subset S$. Without loss of generality it may be assumed that $a p \subset \operatorname{Int} S$ and $p b \subset \operatorname{Ext} S$. Now there exist sequences $D_{1} D_{2} \cdots$ and $C_{1} C_{2} \cdots$ of disks of the collection $V^{*}$ such that for each $i$, (1) $D_{i} \cap a p \neq$ $\phi$, (2) $C_{i} \cap p b \neq \phi$, and (3) there exist homeomorphisms $f_{i}$ and $g_{i}$ of $D_{i}$ and $C_{i}$, respectively, onto $D$ which move no point more than $1 / i$.

Let $D^{\prime \prime}$ be a subdisk of $D^{\prime}$ such that $p \in \operatorname{Int} D^{\prime \prime}$ and $D^{\prime \prime} \subset \operatorname{Int} D^{\prime}$. Now without loss of generality it may be assumed that each of $f_{1}^{-1}\left(D^{\prime \prime}\right)$, $f_{2}^{-1}\left(D^{\prime \prime}\right) \cdots$ lies in Int $S$ and that each of $g_{1}^{-1}\left(D^{\prime \prime}\right), g_{2}^{-1}\left(D^{\prime \prime}\right) \cdots$ lies in Ext $S$. It follows from Theorem 9 of [1] that $S$ is locally tame at $p$ and hence that $D$ is locally tame at $p$. This establishes Lemma 2.

Lemma 3. If $D$ is a disk in $E^{3}$ and $D$ is locally tame at each point of Int $D$ then $D$ lies on a 2-sphere in $E^{3}$.

Proof. Let $D$ be a disk in $E^{3}$ which is locally tame at each point of Int $D$. It follows from [5] that there exists a homeomorphism $h$ of $E^{3}$ onto itself such that $h(D)$ is locally polyhedral except on $h(B d D)$. It follows from the proof of Lemma 5.1 of [4] that there exists a 2sphere $S$ in $E^{3}$ such that $h(D) \subset S$. Then $h^{-1}(S)$ is a 2-sphere in $E^{3}$ such that $D \subset h^{-1}(S)$. This establishes Lemma 3 .

\section{REFERENCES}

1. R. H. Bing, A surface is tame if its complement is 1-ULC, Trans. Amer. Math. Soc., 101 (1961), 294-305.

2. Conditions under which a surface in $E^{3}$ is tame, Fund. Math., 47 (1959), 105-139.

3. K. Borsuk, Sur les rétracts, Fund. Math., 17 (1931), 152-170.

4. O. G. Harrold, H. C. Griffeth and E. E. Posey, A characterization of tame curves in three space, Trans. Amer. Math. Soc., 79 (1955), 12-34.

5. E. E. Moise, Affine structures in 3-manifolds, IV. Piecewise linear approximations of homeomorphisms, Ann. of Math., 55 (1952), 215-222.

6. J. R. Stallings, Uncountably many wild disks, Ann. of Math., 71 (1960), 185-186.

The Institute For AdVANCED StUdy 



\section{PACIFIC JOURNAL OF MATHEMATICS}

\section{EDITORS}

RalPh S. Phillips

Stanford University

Stanford, California

M. G. Arsove

University of Washington

Seattle 5 , Washington
J. Dugundu

University of Southern California

Los Angeles 7, California

Lowell J. Paige

University of California

Los Angeles 24, California

\section{ASSOCIATE EDITORS}
E. F. BECKENBACH
D. DERRY
H. L. ROYDEN
E. G. STRAUS
T. M. CHERRY
M. OHTSUKA
E. SPANIER
F. WOLF

\section{SUPPORTING INSTITUTIONS}

\author{
UNIVERSITY OF BRITISH COLUMBIA \\ CALIFORNIA INSTITUTE OF TECHNOLOGY \\ UNIVERSITY OF CALIFORNIA \\ MONTANA STATE UNIVERSITY \\ UNIVERSITY OF NEVADA \\ NEW MEXICO STATE UNIVERSITY \\ OREGON STATE UNIVERSITY \\ UNIVERSITY OF OREGON \\ OSAKA UNIVERSITY \\ UNIVERSITY OF SOUTHERN CALIFORNIA
}

\author{
STANFORD UNIVERSITY \\ UNIVERSITY OF TOKYO \\ UNIVERSITY OF UTAH \\ WASHINGTON STATE UNIVERSITY \\ UNIVERSITY OF WASHINGTON \\ AMERICAN MATHEMATICAL SOCIETY \\ CALIFORNIA RESEARCH CORPORATION \\ SPACE TECHNOLOGY LABORATORIES \\ NAVAL ORDNANCE TEST STATION
}

Mathematical papers intended for publication in the Pacific Journal of Mathematrcs should be typewritten (double spaced), and the author should keep a complete copy. Manuscripts may be sent to any one of the four editors. All other communications to the editors should be addressed to the managing editor, L. J. Paige at the University of California, Los Angeles 24, California.

50 reprints per author of each article are furnished free of charge; additional copses may be obtained at cost in multiples of 50 .

The Pacific Journal of Mathematics is published quarterly, in March, June, September, and December. Effective with Volume 13 the price per volume (4 numbers) is $\$ 18.00$; single issues, $\$ 5.00$. Special price for current issues to individual faculty members of supporting institutions and to individual members of the American Mathematical Society: $\$ 8.00$ per volume; single issues $\$ 2.50$. Back numbers are available.

Subscriptions, orders for back numbers, and changes of address should be sent to Pacific Journal of Mathematics, 103 Highland Boulevard, Berkeley 8, California.

Printed at Kokusai Bunken Insatsusha (International Academic Printing Co., Ltd.), No. 6 , 2-chome, Fujimi-cho, Chiyoda-ku, Tokyo, Japan.

\section{PUBLISHED BY PACIFIC JOURNAL OF MATHEMATICS, A NON-PROFIT CORPORATION}

The Supporting Institutions listed above contribute to the cost of publication of this Journal, but they are not owners or publishers and have no responsibility for its content or policies. 


\section{Pacific Journal of Mathematics}

\section{Vol. 13, No. $4 \quad$ June, 1963}

Dallas O. Banks, Bounds for eigenvalues and generalized convexity ........... 1031

Jerrold William Bebernes, A subfunction approach to a boundary value problem for

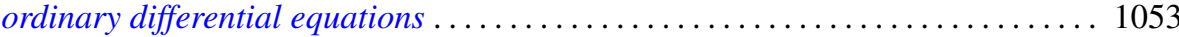

Woodrow Wilson Bledsoe and A. P. Morse, A topological measure construction . . . 1067

George Clements, Entropies of several sets of real valued functions . . . . . . . . . 1085

Sandra Barkdull Cleveland, Homomorphisms of non-commutative *-algebras . . . . . 1097

William John Andrew Culmer and William Ashton Harris, Convergent solutions of

ordinary linear homogeneous difference equations . . . . . . . . . . . . . . . 1111

Ralph DeMarr, Common fixed points for commuting contraction mappings . . . . . . 1139

James Robert Dorroh, Integral equations in normed abelian groups . . . . . . . . 1143

Adriano Mario Garsia, Entropy and singularity of infinite convolutions . . . . . . . 1159

J. J. Gergen, Francis G. Dressel and Wilbur Hallan Purcell, Jr., Convergence of extended Bernstein polynomials in the complex plane ................. 1171

Irving Leonard Glicksberg, A remark on analyticity of function algebras . . . . . . 1181

Charles John August Halberg, Jr., Semigroups of matrices defining linked operators

with different spectra ................................. 1187

Philip Hartman and Nelson Onuchic, On the asymptotic integration of ordinary

differential equations . . . . . . . . . . . . . . . . . . . . . . . . . . . . 1193

Isidore Heller, On a class of equivalent systems of linear inequalities . . . . . . . . . 1209

Joseph Hersch, The method of interior parallels applied to polygonal or multiply

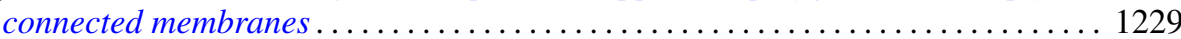

Hans F. Weinberger, An effectless cutting of a vibrating membrane . . . . . . . . . . 1239

Melvin F. Janowitz, Quantifiers and orthomodular lattices ....

Samuel Karlin and Albert Boris J. Novikoff, Generalized convex inequalities . .

Tilla Weinstein, Another conformal structure on immersed surfaces of negative

curvature.

Gregers Louis Krabbe, Spectral permanence of scalar operators

Shige Toshi Kuroda, Finite-dimensional perturbation and a representaion of

scattering operator.

Marvin David Marcus and Afton Herbert Cayford, Equality in certain

inequalities

Joseph Martin, A note on uncountably many disks .

Eugene Kay McLachlan, Extremal elements of the convex cone of semi-norms . . . . 1335

John W. Moon, An extension of Landau's theorem on tournaments . .

Louis Joel Mordell, On the integer solutions of $y(y+1)=x(x$

Kenneth Roy Mount, Some remarks on Fitting's invariants .....

Miroslav Novotný, Über Abbildungen von Mengen ............

Robert Dean Ryan, Conjugate functions in Orlicz spaces.

John Vincent Ryff, On the representation of doubly stochastic operators . . . . . . . . 1379

Donald Ray Sherbert, Banach algebras of Lipschitz functions .

James McLean Sloss, Reflection of biharmonic functions across analytic boundary

conditions with examples.

L. Bruce Treybig, Concerning homogeneity in totally ordered, connected topological space....

John Wermer, The space of real parts of a function algebra...

James Juei-Chin Yeh, Orthogonal developments of functionals and related theorems

in the Wiener space of functions of two variables......... 